\title{
Modified Dynamically-updated Weighted Opportunity Cost Based Algorithm for Unbalanced Transportation Problem
}

\author{
A R M Jalal Uddin Jamali* and Ringku Rani Mondal \\ Dept. of Mathematics, Khulna University of Engineering \& Technology, Khulna 9203, Bangladesh
}

Received: 04 April 2021

Accepted: 28 June 2021

\begin{abstract}
Recently, Weighted Opportunity Cost (WOC) based algorithms are developed for solving balanced Transportation Problems (TPS). The exceptionality of the WOC based approaches is to introduce supply and demand as weight factor to cost entries for the control of flow of allocations. But in the unbalanced TP, there exist a pitfall whenever balancing the TP with zero dummy transportation cost as done in existing classical approaches, so that the total cost is unaffected due to dummy transportations. A modified dynamically-updated weighted opportunity cost-based algorithm embedded on Least Cost Method (LCM) is proposed which is suitable for both balanced and unbalanced TPS. Numerical instances have been carried out to demonstrate the effectiveness and efficiency of the proposed method. It is observed that, the proposed modified dynamically-updated weighted opportunity cost-based algorithm sometimes outperforms for the LCM as well as the existing weighted opportunity cost-based algorithm in unbalanced TPS.
\end{abstract}

Keywords: Cost matrix; Dummy route; Least Cost method; Transportation; Unbalanced Problem; Weighted Opportunity Cost.

\section{INTRODUCTION}

Finding Initial Basic Feasible Solution (IBFS) is an important step to obtain an optimal solution of any balanced and unbalanced TPs. The initial transportation problem was basically developed by F.L. Hitchcock in 1941 and referred as Least Cost Method (LCM) which allocating in the lowest cost cell in every turn of allocation of transportation problem. In 1947, T. C. Koopmans developed a method, named Simplex Method. It is observed that TP can be converted to a standard Linear Programming Problem (LPP) and it can be solved by Simplex Method but it is time consuming. In 1954, Cooper et al. introduced North-West Corner (NWC) method which allocating the first row and first column cell or north-west corner cell. It depends on position but not transportation cost that's why it's usually yields higher cost which is much more than optimal cost. So, it's trustworthy that LCM is much better than NWC method. Vogel's Approximation Method (VAM) developed by Reinfeld and Vogel, in 1958 which yields better solution than LCM and NWC method. This method is described with penalty which calculates the difference of the lowest cost and next to the lowest cost in each row and column of transportation table and the allocation procedure starts with the lowest cost cell corresponding to the highest penalty. In 1984, Goyal improved VAM for the unbalanced TP by adding the maximal cost for the dummy. Ramakrishnan proposed an improvement version of Goyal's modified VAM for the unbalanced transportation problem in 1988. In 2015, Soomro et al. developed Modified Vogel's Approximation Method (MVAM). Korukoglu et al., in 2011, introduced the Total Opportunity Matrix (TOM) by manipulating cost entries rather than Distribution Indicator (DI) used in VAM to determine the flow of allocations. Azad and Hossain presented a new method for IBFS by calculating the Average Row Penalty (ARP) and the Average Column Penalty (ACP) in 2017. Kaur et al. (2019) proposed another approach for obtaining IBFS of balanced TPs, which is based on making allocations in zero cost cells of reduced transportation table. In this method, select the rows/columns are fixed and select minimum value of each row/column and calculate the subtraction of minimum cost of each row/column from all costs of corresponding row/column. Hossain et al. (2020) proposed a comparative study for finding IBFS according to the Least Cost Mean Method (LCMM) where row penalty and column penalty are brought out by the mean of lowest and next lowest cost of each row and each column of the cost matrix. Then, allocate the minimum value of supply and demand to the cell having lowest unit transportation cost in the row or column along which the highest penalty cost appears. Actually, all of the methods discussed, in addition, most of the methods available in the literature are based on VAMs. These all methods are built on manipulations of cost entries for the flows of allocation precedence. None considers supply/demand entries for the flow of allocations. Recently, Jamali et al. (2017) introduced a new concept for controlling the flow of allocations in the case of IBFS of balanced TPs. They developed WOC matrix to control the flow of allocations. In WOC, the amount of supply and demand acts as 
weight factor upon each cost entry. In Jamali et al. (2017), by incorporating the concept of WOC on LCM they proposed a new algorithm for solving balanced TPS. But in Jamali and Akter (2017), the WOC matrix is not updated during flow of allocation. Later Jamali et al. (2018) proposed a modified WOC based algorithm, named as, Sequentially Updated WOC-LCM (SUWOC-LCM) for balanced TPs in which WOC matrix is updating during flow of allocations. Kenan et al. (2020) proposed a novel approximation method to obtain the IBFS of the balanced TPs. This method, built heuristic structure, which takes into account the supply-demand coverage ratio (weights) as well as the cost.

But in real-life most of the TPs are unbalanced. To solve unbalanced TP, the existing approaches first create new dummy routes with zero transportation cost to make it balanced. Though both WOC based and modified WOC based algorithms are good enough for finding IBFS of balanced TPs, but due to zero cost on dummy routes both approaches find drawback for unbalanced TPs.

Very recently, Jamali et al. (2019) proposed a modified WOC based algorithms (MWOC-LCM) for finding IBFS which is suitable for both balanced and unbalanced TPs. But in Jamali et al. (2019), the modified WOC is not updated during flow of allocations. It is worthwhile to mention here that, WOC is formulated in such way that the cell (route) with larger availability of commodity gets higher weight. At the same time the route with smaller transportation cost gets preference like LCM. That is, the rule of flow of allocation is - highest weighted cost prefer first. In modified updated WOC based approach, WOC matrix is sequentially updated after each allocation.

The paper is organized as follows. The mathematical model of balanced TP is presented in section 2.1. In section 2.2 the algorithm of WOC is discussed briefly. In section 3.1, we have described the procedure to solve the unbalanced TP suitable for WOC based approach. The proposed modified dynamically-updated weighted opportunity cost based algorithm for unbalanced TP is presented in section 3.2. Numerical demonstrations as well as comparisonal studies are discussed in section 4. Finally, conclusion is drawn in section 5.

\section{MATHEMATICAL MODEL OF BALANCED TP}

\subsection{Mathematical model for general transportation problem}

The general form of a transportation problem is given by

$$
\begin{array}{lll}
\text { Minimize } & Z=\sum_{i=1}^{m} \sum_{j=1}^{n} c_{i j} x_{i j} & \text { (Total transportation cost) } \\
\text { Subject to } & \sum_{j=1}^{n} x_{i j}=a_{i}, \quad i=1,2 \cdots, m & \text { (Supplies at origin) } \\
& \sum_{i=1}^{m} x_{i j}=b_{j}, \quad j=1,2, \cdots, n & \text { (Demand at destinations) } \\
x_{i j} \geq 0 \quad \forall i, j & \text { (Quantities) }
\end{array}
$$

It is noted that total supply and total demand are identical in a balanced transportation i.e. $\sum_{i}^{m} \boldsymbol{a}_{i}=\sum_{j}^{n} \boldsymbol{b}_{j}$

But, for unbalanced transportation model they are not equal. It is worthwhile to mention here that, for finding IBFS, the problem should be balanced first.

\subsection{Weighted Opportunity Cost of each Cell $w_{c_{i j}}:$}

In the existing approaches, the flows of transportations are modeled on the basis of cost entries only. But very recently in Jamali et al. (2017), they said that, amount of supply and demand corresponding to each origin and destination may play an important role to control the flow of allocation for finding better IBFS. They developed WOC matrix which is a new concept to control the flow of allocations. In WOC, amount of supply/demand of each route is a weighted factor corresponding to the cost entry.

Step 1 (Finding cell weight): At first, we have found out the maximum possible allocation of the cell $C_{i j}$, which is $\left(S_{i}, D_{j}\right)$, where $S_{i}$ denotes total supply at node $i$ and $D_{j}$ indicates total demand at node $j$. Therefore, sum over of all possible allocations is as follow: 
$\sum_{i=1}^{p} \sum_{j=1}^{q} \min \left(S_{i}, D_{j}\right)$

Therefore, for each cell $C_{i j}$ its weight will be

$\frac{\min \left(S_{i}, D_{j}\right)}{\sum_{i=1}^{p} \sum_{j=1}^{q} \min \left(S_{i}, D_{j}\right)}$, so that total weight becomes one. i.e.,

$\sum_{i=1}^{p} \sum_{j=1}^{q}\left\{\frac{\min \left(S_{i}, D_{j}\right)}{\sum_{i=1}^{p} \sum_{j=1}^{q} \min \left(S_{i}, D_{j}\right)}\right\}=1$

But as each cell contains the factor $\frac{1}{\sum_{i=1}^{p} \sum_{j=1}^{q} \min \left(S_{i}, D_{j}\right)}$, so we have ignored this factor to reduce computational cost. Therefore, for each cell $C_{i j}$ its weight will be $\min \left(S_{i}, D_{j}\right)$. The formulation of WOC matrix $\left[\boldsymbol{w}_{\boldsymbol{c}_{i j}}\right]$ (Jamali et al., 2017) are briefly presented below:

$$
\text { If } c_{i j}>0 \text {, set } \boldsymbol{w}_{\boldsymbol{c}_{i j}}=\frac{1}{\boldsymbol{c}_{i j}} \times \min \left(\boldsymbol{a}_{\boldsymbol{i}}, \boldsymbol{b}_{\boldsymbol{j}}\right)
$$

$$
\begin{aligned}
& \text { Else if } c_{i j}=0 \text { and }\left\{\boldsymbol{c}_{p \boldsymbol{q}}: 0<\boldsymbol{c}_{\boldsymbol{p} q}<1 \forall \boldsymbol{p}, \boldsymbol{q}\right\} \neq \Phi \text { (null set) then set } \boldsymbol{w}_{\boldsymbol{c}_{i j}}=\boldsymbol{M} \times \min \left(\boldsymbol{a}_{\boldsymbol{i}}, \boldsymbol{b}_{\boldsymbol{j}}\right), \\
& \text { where } \boldsymbol{M}=\max \left\{\boldsymbol{a}_{\boldsymbol{p}}, \boldsymbol{b}_{\boldsymbol{q}} \forall \boldsymbol{p}, \boldsymbol{q}\right\} / \min \left\{\boldsymbol{c}_{\boldsymbol{p} \boldsymbol{q}}: 0<\boldsymbol{c}_{\boldsymbol{p} \boldsymbol{q}}<1 \forall \boldsymbol{p}, \boldsymbol{q}\right\} .
\end{aligned}
$$

(iv) Else if $c_{i j}=0$ and $\left\{\boldsymbol{c}_{p q}: 0<\boldsymbol{c}_{p q}<1 \forall \boldsymbol{p}, \boldsymbol{q}\right\}=\Phi$, then set

$$
\boldsymbol{w}_{\boldsymbol{c}_{i j}}=\boldsymbol{N} \times \min \left(\boldsymbol{a}_{\boldsymbol{i}}, \boldsymbol{b}_{\boldsymbol{j}}\right) \text {, where } \boldsymbol{N}=\max \left\{\boldsymbol{a}_{\boldsymbol{i}}, \boldsymbol{b}_{\boldsymbol{j}} \forall \boldsymbol{i}, \boldsymbol{j}\right\} \text {. }
$$

\section{PROPOSED MATHEMATICAL MODEL}

\subsection{Proposed mathematical model for unbalanced TP for WOC based approaches}

It is mentioned earlier that when the TP is unbalanced then it should be converted into balanced TP first. Therefore, in order to make the unbalanced TP to balanced TP it is required to create some dummy routes corresponding to exceed/deficiency of commodities. It is noted that, in all classical approaches, the dummy transportation costs are set zero so that, the total transportation cost will be unaffected due to dummy transportations. Though existing WOC based algorithms (Jamali et al., 2017 and Jamali et al., 2018) perform better corresponding to existing classical approaches for example LCM but WOC based algorithms face a pitfall in the case of unbalanced TP. In each entry of WOC matrix, the cost entry is reversely (if cost is greater than one) multiplied to the weight factor formed by the amount of supply/demand. In the case of zero cost, a large amount is multiplied to the weight factor so that it gets preference first in the allocation procedures. Therefore, if we set zero dummy transportation cost for each dummy route, then the value of each entry corresponding to each dummy cost become very large and get preference first. Therefore, a large amount will be allocated to dummy routes first. In consequences, algorithm bound to allocate a large amount of goods to the destinations with larger transportation cost. Indeed, the total transportation cost of IBFS becomes huge. Besides, whatever be the unit transportation cost corresponding to dummy node, the total transportation of IBFS of the algorithm will be affected by the dummy transportation cost if any. But the total transportation cost should be ineffective for dummy transportation. To escape from such a pitfall, here we have proposed a modified mathematical model for solving WOC based algorithm suitable for both balanced and unbalanced TPs. It is worthwhile to mention here that, the existing WOC based algorithms are good for classical mathematical model of balanced TPs. The first step of the proposed WOC based algorithm is to create dummy routes for balancing the problem regarding total supply and total demand in a tricky way given as follow:

Step 1: Find out the exceed amount and creating the dummy origin or destination:

(i) If $\sum_{i}^{m} a_{i}-\sum_{j}^{n} b_{j}=c>0$, then introduce a dummy destination such that $b_{n+1}=c$, so

$$
\sum_{i}^{m} a_{i}=\sum_{j}^{n+1} b_{j}, \text { and set } p=m ; q=n+1 .
$$

(ii) If $\sum_{i}^{m} a_{i}-\sum_{j}^{n} b_{j}=c<0$, then introduce a dummy origin such that $a_{m+1}=c$, so 


$$
\sum_{i}^{m+1} a_{i}=\sum_{j}^{n} b_{j}, \text { and set } p=m+1 ; q=n \text {. }
$$

After creating the routes, our next step is to formulate the mathematical model suitable for Proposed WOC based algorithm.

Step 2: Reformulation of mathematical model of TP

$$
\begin{array}{lll}
\text { Minimize } & Z=\sum_{i=1}^{m} \sum_{j=1}^{n} c_{i j} x_{i j} & \text { (Total transportation cost) } \\
\text { Subject to } & \sum_{j=1}^{q} x_{i j}=a_{i}, \quad i=1,2 \cdots, p & \text { (Supplies at origin) } \\
\sum_{i=1}^{p} x_{i j}=b_{j}, \quad j=1,2, \cdots, q & \text { (Demands at destination) } \\
x_{i j} \geq 0 \quad \forall i, j & \text { (Quantities) } \\
\text { and obviously, } \sum_{i}^{p} a_{i}=\sum_{j}^{q} b_{j} & \text { (Balanced condition) }
\end{array}
$$

After the reformulation of TP, we represent it as a transportation tableau. It is worthwhile to mention here that, in the case of unbalanced TPs, the formulation of total cost is unchanged whereas constraints are changed due to dummy routes (index $m$ and $n$ are replaced by $p$ and $q$ respectively).

\subsection{Proposed Modified Dynamically-updated Weighted Opportunity Cost based LCM Approach}

Since zero transportation cost corresponding to dummy routes causes a pitfall in exiting SUWOC-LCM approach (Jamali and Akter, 2018), we have introduced largest transportation cost namely sum of all costs to each dummy route rather than zero. Due to non-zero transportation costs in dummy routes the algorithm faces new crisis again. To overcome this drawback, in calculating the transportation cost, we will propose a modified SUWOC-LCM that will be able to skip all dummy transportation costs algorithmically, if any. It is noted that the proposed method will be applicable to solve both balanced and unbalanced TPs. The detail description of the proposed a modified Dynamically-updated Weighted Opportunity Cost based LCM approach based on SUWOC-LCM approach and named as Modified Dynamically-updated Weighted Opportunity Cost based LCM (MDWOC-LCM) approach is given below.

\subsubsection{Formulation of transportation model for unbalanced TP and WOC matrix}

The Mathematical reformulation of unbalanced TPs for making balanced TP is same as described at Section 3.1 which is as follows:

Step 1 (Find out the exceed amount and identify the dummy origin or destination):

(a) If $\sum_{i}^{m} a_{i}-\sum_{j}^{n} b_{j}=c>0$ then introduce a dummy destination such that $b_{n+1}=c$, so

$$
\sum_{i}^{m} a_{i}=\sum_{j}^{n+1} b_{j} ; \text { in addition, set } p=m ; q=n+1
$$

(b) If $\sum_{i}^{m} a_{i}-\sum_{j}^{n} b_{j}=c<0$, then introduce a dummy origin such that $a_{m+1}=c$, so

$$
\sum_{i}^{m+1} a_{i}=\sum_{j}^{n} b_{j} ; \text { and set } p=m+1 ; q=n
$$

(c) Finally, mathematical model of cost minimization of the TP

$$
\begin{array}{ll}
\text { Minimize } Z=\sum_{i=1}^{m} \sum_{j=1}^{n} c_{i j} x_{i j} & \text { (Total transportation cost) } \\
\text { Subject to } \sum_{j=1}^{q} \boldsymbol{x}_{i j}=\boldsymbol{a}_{i}, \quad \boldsymbol{i}=1,2, \cdots, \boldsymbol{p} & \text { (Supplies at origin) }
\end{array}
$$




$$
\begin{array}{cl}
\sum_{i=1}^{p} x_{i j}=b_{j}, \quad j=1,2, \cdots, q & \text { (Demands at destination) } \\
x_{i j} \geq 0 \quad \forall i, j & \text { (Quantities) } \\
\text { and obviously, } \sum_{i}^{p} a_{i}=\sum_{j}^{q} b_{j} & \text { (Balanced condition) }
\end{array}
$$

\subsubsection{Formulation of weighted opportunity cost (WOC) matrix}

The formulation of WOC is (also similar as in Section 2.2) briefly presented below:

Step 2 (Finding cell weight): At first, we have found out the maximum possible allocation of the cell $c_{i j}$, which is indeed $\min \left(S_{i}, D_{j}\right)$, where $S_{i}$ denotes total supply at node $i$ and $D_{j}$ indicates total demand at node $j$. Therefore, for each cell $C_{i j}$, its weight will be $\min \left(S_{i}, D_{j}\right)$, (for details see Section 2.2).

Step 3 (Formulation of WOC matrix): The formulation of WOC is given below:

(a) If $c_{s t} \neq 0$, then $w_{c_{i j}}=\frac{1}{c_{i j}} \times \frac{\min \left(S_{i}, D_{j}\right)}{\sum_{i=1}^{p} \sum_{j=1}^{q \sum} \min \left(S_{i}, D_{j}\right)}$

where $\boldsymbol{w}_{c_{i j}}$ and $c_{i j}$ denote weighted opportunity cost and actual cost corresponding to the cell $C_{i j}$, respectively.

However, in the case of $c_{i j}=0$, we have

(b) If $c_{s t}=0$ and $\left\{c_{i j}: 0<c_{i j}<1 \forall i, j\right\} \neq \Phi$ (i.e. null set), then set

$$
\boldsymbol{w}_{\boldsymbol{c}_{s t}}=\boldsymbol{M} \times \min \left(\boldsymbol{a}_{\boldsymbol{i}}, \boldsymbol{b}_{j}\right),
$$

where, $\boldsymbol{M}=\max \left\{\boldsymbol{a}_{\boldsymbol{i}}, \boldsymbol{b}_{\boldsymbol{j}} \forall \boldsymbol{i}, \boldsymbol{j}\right\} / \min \left\{\boldsymbol{c}_{\boldsymbol{i} \boldsymbol{j}}: 0<\boldsymbol{c}_{\boldsymbol{i j}}<1 \quad \forall \boldsymbol{i}, \boldsymbol{j}\right\}$.

Else if $c_{s t}=0$ and $\left\{c_{i j}: 0<c_{i j}<1 \quad \forall \boldsymbol{i}, \boldsymbol{j}\right\}=\Phi$, set

$\boldsymbol{w}_{\boldsymbol{c}_{s t}}=\boldsymbol{N} \times \min \left(\boldsymbol{a}_{\boldsymbol{i}}, \boldsymbol{b}_{\boldsymbol{j}}\right)$, where $\boldsymbol{N}=\max \left\{\boldsymbol{a}_{\boldsymbol{i}}, \boldsymbol{b}_{\boldsymbol{j}} \forall \boldsymbol{i}, \boldsymbol{j}\right\}$.

Therefore, in this way a WOC matrix will be formulated.

\subsubsection{Formulation of unit cost at dummy route}

Further task is to define the amount of unit transportation cost for each dummy route (cell). We need to define it in such a way that this route has least weighted opportunity cost but in the same time it should be generic. Therefore, we set unit transportation cost $=\sum_{i=1}^{m} \sum_{j=1}^{n} c_{i j} x_{i j} \quad$ corresponding to each dummy route.

\subsubsection{Procedure of Dynamically Updating of WOC matrix}

We have already formulated the general formula for finding WOC of each cell $\boldsymbol{w}_{\boldsymbol{c}_{\boldsymbol{i}}}$ as given by (i) - (ii) in Section 2.2.

\section{Allocation procedure:}

Allocate amount of $\min \left(a_{i}, b_{j}\right)$ at cell $C_{i j}$ such that, $\boldsymbol{w}_{\boldsymbol{c}_{i j}}=\max \left\{\boldsymbol{w}_{\boldsymbol{c}_{\boldsymbol{p} q}} ; \forall \boldsymbol{p}, \boldsymbol{q}\right\}$.

After allocating the first term, we have to update the WOC matrix by following instructions. It is worthwhile to mention here that, the algorithm actually needs not to update the cost matrix at the same time. 


\section{Updating WOC based transportation tableau:}

$$
\text { If } \boldsymbol{a}_{\boldsymbol{i}}=\min \left(\boldsymbol{a}_{\boldsymbol{i}}, \boldsymbol{b}_{\boldsymbol{j}}\right) \text { then set } a_{i}=0 \text { and cross out } c_{i q} \text { and } \boldsymbol{w}_{\boldsymbol{c}_{\boldsymbol{i q}}} \forall \boldsymbol{q} \text { and then }
$$

(a) Update demand $b_{j}{ }^{\prime}=\left|b_{j}-a_{i}\right|$;

(b) Update $j^{\text {th }}$ column of WOC matrix $\left[\boldsymbol{w}_{\boldsymbol{c}_{i j}}\right]$ such that

$$
\boldsymbol{w}_{\boldsymbol{c}_{p j}}^{\prime}=\boldsymbol{w}_{\boldsymbol{c}_{p j}} \times \min \left\{\boldsymbol{a}_{\boldsymbol{p}}, \boldsymbol{b}_{j}^{\prime}\right\} / \min \left(\boldsymbol{a}_{\boldsymbol{p}}, \boldsymbol{b}_{j}\right) \forall \boldsymbol{p} .
$$

(ii) Else set $b_{j}=0$ and cross out $c_{p j}$ and $\boldsymbol{w}_{\boldsymbol{c}_{p j}} \forall \boldsymbol{p}$ and then

(a) Update supply $a_{i}{ }^{\prime}=\left|b_{j}-a_{i}\right|$;

(b) Update $i^{\text {th }}$ row of WOC matrix $\left[\boldsymbol{w}_{\boldsymbol{c}_{i j}}\right]$ such that

$$
\boldsymbol{w}_{\boldsymbol{c}_{i q}}^{\prime}=\boldsymbol{w}_{\boldsymbol{c}_{i q}} \times \min \left\{\boldsymbol{a}_{\boldsymbol{i}}^{\prime}, \boldsymbol{b}_{\boldsymbol{q}}\right\} / \min \left(\boldsymbol{a}_{\boldsymbol{i}}, \boldsymbol{b}_{\boldsymbol{q}}\right) \forall \boldsymbol{q}
$$

Termination condition: Repeat the procedure unless termination condition meets.

Total cost: Calculate the total transportation cost by ignoring dummy transportation cost if any by using the formula $Z=\sum_{i=1}^{m} \sum_{j=1}^{n} c_{i j} x_{i j}$

\subsection{Experimentation and Discussion:}

For better explanation of the proposed algorithm, we have considered a typical unbalanced TP as follows:

Table 1: An unbalanced transportation tableau

\begin{tabular}{c|l|l|l|l}
\multicolumn{1}{c}{} & $\mathrm{D}_{1}$ & $\mathrm{D}_{2}$ & \multicolumn{1}{c}{$\mathrm{D}_{3}$} & Supply \\
$\mathrm{O}_{1}$ & 3 & 5 & 10 & 50 \\
$\mathrm{O}_{2}$ & 6 & 4 & 5 & 20 \\
$\mathrm{O}_{3}$ & 4 & 6 & 7 & 15 \\
\cline { 2 - 4 } Demand & 15 & 30 & 45 &
\end{tabular}

Solution: The first step for the solution procedure is making the unbalanced TP to balanced TP. As total demand is exceeded by the amount of five from the total demand, so we need a dummy origin with amount 5 namely $\mathrm{O}_{4}$ (see in the Table 2). Now, we have to set dummy transportation cost corresponding to all dummy routes which is given by the formula $\sum_{i=1}^{m} \sum_{j=1}^{n} c_{i j}=50$. Therefore, the balanced TP of the given unbalanced TP is shown in Table 2.

Table 2: The Balance TP after induced dummy highest cost source

$$
\begin{aligned}
& \mathrm{O}_{1} \\
& \mathrm{O}_{2} \\
& \mathrm{O}_{3} \\
& \mathrm{O}_{4}
\end{aligned}
$$

\begin{tabular}{|l|l|l|l}
\multicolumn{1}{l|}{$\mathrm{D}_{1}$} & $\mathrm{D}_{2}$ & \multicolumn{1}{c}{ Supply } \\
\hline 3 & 5 & 10 & 50 \\
\cline { 1 - 2 } 6 & 4 & 5 & 20 \\
\cline { 1 - 2 } & 6 & 7 & 15 \\
\cline { 1 - 2 } 50 & 50 & 50 & 5 \\
\hline
\end{tabular}

Demand

15

30

45


Now we have to find out the initial WOC matrix of the balanced TP according to the rules given in Section 3.2.2. The WOC matrix is shown in Table 3.

Table 3: WOC matrix corresponding to the balanced TT

\begin{tabular}{|c|c|c|c|c|c|c|c|}
\hline & $\mathrm{D}_{1}$ & & $\mathrm{D}_{2}$ & & $\mathrm{D}_{3}$ & & Supply \\
\hline $\mathrm{O}_{1}$ & 5 & 3 & 6 & 5 & 4.5 & 10 & 50 \\
\hline $\mathrm{O}_{2}$ & 2.5 & 6 & 5 & 4 & 4 & 5 & 20 \\
\hline $\mathrm{O}_{3}$ & 3.75 & 4 & 2.5 & 6 & 2.14 & 7 & 15 \\
\hline $\mathrm{O}_{4}$ & 0.1 & 50 & 0.1 & 50 & 0.1 & 50 & 5 \\
\hline Demand & 15 & & 30 & & 45 & & \\
\hline
\end{tabular}

Now we will discuss the allocation procedure of the proposed MDWOC-LCM approach step by step. The procedure of each step of the proposed algorithm is shown in tables. In the cost table (a sub-table which contain cost entries) each cell contained for entries - the value at upper right corner indicates transportation cost, the value at upper left corner indicates weighted cost, the value at lower left corner indicates amount of allocation and the value at lower right corner indicates number of steps.

Now it is observed that the highest weighted cost is 6 corresponding to cell $\mathrm{C}_{12}$ and possible amount of commodity is 30 . So, we have allocated this amount to that cell. After the first allocation which is shown in Table 4, we need to update the TT as well as WOC matrix.

Table 4: After $1^{\text {st }}$ allocation of the proposed MDWOC-LCM approach

\begin{tabular}{|c|c|c|c|c|c|c|c|}
\hline & $\mathrm{D}_{1}$ & & $\mathrm{D}_{2}$ & \multicolumn{3}{|c|}{$\mathrm{D}_{3}$} & \multirow{2}{*}{$\begin{array}{l}\text { Supply } \\
50,20\end{array}$} \\
\hline $\mathrm{O}_{1}$ & 5 & 3 & & $\begin{array}{l}5 \\
1\end{array}$ & 4.5 & 10 & \\
\hline $\mathrm{O}_{2}$ & 2.5 & 6 & & 4 & 4 & 5 & 20 \\
\hline $\mathrm{O}_{3}$ & 3.75 & 4 & $\begin{array}{l}2.5 \\
\times\end{array}$ & 6 & 2.14 & 7 & 15 \\
\hline $\mathrm{O}_{4}$ & 0.1 & 50 & $\begin{array}{l}0.1 \\
\times\end{array}$ & 50 & 0.1 & 50 & 5 \\
\hline emand & 15 & & 30 & & 45 & & \\
\hline
\end{tabular}

Table 5: After $2^{\text {nd }}$ allocation of the proposed MDWOC-LCM approach
$\mathrm{D}_{1}$
$\mathrm{D}_{2}$
$\mathrm{D}_{3}$
Supply

\begin{tabular}{|c|c|c|c|c|c|c|c|}
\hline $\mathrm{O}_{1}$ & 5 & 3 & & 5 & $4.5,2$ & 10 & $5 \theta, 2 \theta, 5$ \\
\hline $\mathrm{O}_{2}$ & $\begin{array}{l}15 \\
2.5 \\
\times\end{array}$ & 6 & $\begin{array}{l}50 \\
5 \\
\times\end{array}$ & 4 & 4 & 5 & 20 \\
\hline $\mathrm{O}_{3}$ & $\begin{array}{l}3.75 \\
\times\end{array}$ & 4 & $\begin{array}{l}2.5 \\
\times\end{array}$ & 6 & 2.14 & 7 & 15 \\
\hline $\mathrm{O}_{4}$ & $\begin{array}{l}0.1 \\
\times\end{array}$ & 50 & $\begin{array}{l}0.1 \\
\times\end{array}$ & 50 & 0.1 & 50 & 5 \\
\hline emand & 15 & & 30 & & 45 & & \\
\hline
\end{tabular}

As commodity is allocated to the cell $\mathrm{C}_{12}$, so after the $1^{\text {st }}$ allocation we need to update the supply and demand value of WOC-TT matrix of $1^{\text {st }}$ row and second column. Since the demand value of cell $\mathrm{C}_{12}$ is minimum so we have updated the corresponding supply value i.e., $(50-30)=20$. In addition, the corresponding demand value is vanished. 
Now we need to update the WOC matrix. Since demand of $\mathrm{D}_{2}$ is vanished so algorithm will ignore the cells corresponding to the column 2. Again, since the amount of first row (supply) is changed so we need to update all remain cells corresponding to origin $\mathrm{O}_{1}$. Since $\mathrm{C}_{11}$ cell contains the minimum demand (15) than corresponding to the new supply (20), so it will not be changed. But, the cell $\mathrm{C}_{13}$ contains the minimum new supply value (20) than the corresponding demand value (45), so the weighted cost in this cell will be changed which is $(20 / 10)=2$.

Table 6: After $3^{\text {rd }}$ allocation of the proposed MDWOC-LCM approach

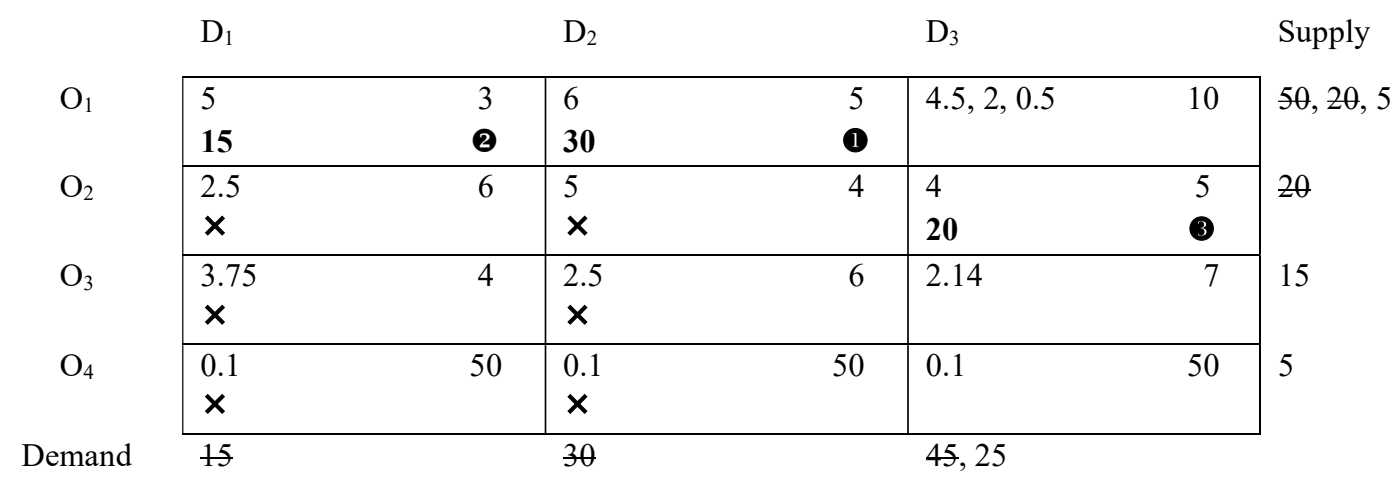

Table 7: After $4^{\text {th }}$ allocation of the proposed MDWOC-LCM approach

\begin{tabular}{|c|c|c|c|c|c|c|c|}
\hline & \multicolumn{2}{|l|}{$\mathrm{D}_{1}$} & \multicolumn{2}{|l|}{$\mathrm{D}_{2}$} & \multicolumn{2}{|l|}{$\mathrm{D}_{3}$} & \multirow{2}{*}{$\begin{array}{l}\text { Supply } \\
50,20,5\end{array}$} \\
\hline $\mathrm{O}_{1}$ & $\begin{array}{l}5 \\
15\end{array}$ & $\begin{array}{l}3 \\
2\end{array}$ & & $\begin{array}{l}5 \\
1\end{array}$ & $4.5,2$ & 10 & \\
\hline $\mathrm{O}_{2}$ & $\begin{array}{l}2.5 \\
\times\end{array}$ & 6 & & 4 & & $\begin{array}{l}5 \\
3\end{array}$ & 20 \\
\hline $\mathrm{O}_{3}$ & $\begin{array}{l}3.75 \\
\times\end{array}$ & 4 & $\begin{array}{l}2.5 \\
\times\end{array}$ & 6 & $\begin{array}{l}2.14 \\
15\end{array}$ & $\begin{array}{l}7 \\
\mathbf{4}\end{array}$ & 15 \\
\hline $\mathrm{O}_{4}$ & $\begin{array}{l}0.1 \\
\times\end{array}$ & 50 & $\begin{array}{l}0.1 \\
\times\end{array}$ & 50 & 0.1 & 50 & 5 \\
\hline Demand & 15 & & 30 & & 45 , & & \\
\hline
\end{tabular}

Table 8: After $5^{\text {th }}$ allocation of the proposed MDWOC-LCM approach

$\begin{array}{llll}\mathrm{D}_{1} & \mathrm{D}_{2} & \mathrm{D}_{3} & \text { Supply }\end{array}$

\begin{tabular}{|c|c|c|c|c|c|c|c|}
\hline $\mathrm{O}_{1}$ & $\begin{array}{l}5 \\
15\end{array}$ & $\begin{array}{r}3 \\
2\end{array}$ & $\begin{array}{l}6 \\
30\end{array}$ & $\begin{array}{r}5 \\
1\end{array}$ & $\begin{array}{l}4.5,2 \\
5\end{array}$ & $\begin{array}{l}10 \\
\mathbf{5}\end{array}$ & \multirow[b]{2}{*}{20} \\
\hline $\mathrm{O}_{2}$ & & 6 & $\begin{array}{l}5 \\
\times\end{array}$ & 4 & & $\begin{array}{r}5 \\
3\end{array}$ & \\
\hline $\mathrm{O}_{3}$ & $\begin{array}{l}3.75 \\
\times\end{array}$ & 4 & $\begin{array}{l}2.5 \\
\times\end{array}$ & 6 & $\begin{array}{l}2.14 \\
15\end{array}$ & $\begin{array}{r}7 \\
\mathbf{4}\end{array}$ & \multirow[t]{2}{*}{15} \\
\hline $\mathrm{O}_{4}$ & $\begin{array}{l}0.1 \\
\times\end{array}$ & 50 & $\begin{array}{l}0.1 \\
\times\end{array}$ & 50 & 0.1 & 50 & \\
\hline Demand & 15 & & 30 & & 45 & & \\
\hline
\end{tabular}

After update the WOC matrix, the algorithm intends to allocate the next cell. It is observed that the remaining highest weighted cost is 5 contained at the cell $\mathrm{C}_{11}$. So, our next allocation cell will be $\mathrm{C}_{11}$. Here, demand value of $\mathrm{D}_{1}$ is 15 which is lower than the supply value of $\mathrm{O}_{1}$ which is 20 . Since demand is minimum, so we have to 
allocate the total amount of demand in cell $\mathrm{C}_{11}$ and after allocating, demand cell will be vanished. Now we need to update the supply value, the new supply value of $D_{1}$ is $(20-15)=5$. Again, this new supply value is minimum corresponding to the demand value of cell $\mathrm{C}_{13}$. So, we need to update the weighted cost of $\mathrm{C}_{13}$ i.e., $(5 / 10)=0.5$. Moreover, since the demand of destination of $D_{1}$ is satisfied so the column of $D_{1}$ is vanished. Then update result is shown in Table 5 .

We have allocated systematically according to the proposed MDWOC-LCM approach. The systematic allocation procedures are shown on the following Tables 6, 7,8 and 9 respectively and after completion of all allocations, we have the IBFS.

Table 9: After all allocations of proposed MDWOC-LCM

\begin{tabular}{|c|c|c|c|c|c|c|c|}
\hline & $\mathrm{D}_{1}$ & & $\mathrm{D}_{2}$ & & $\mathrm{D}_{3}$ & & Supply \\
\hline $\mathrm{O}_{1}$ & $\begin{array}{l}5 \\
15\end{array}$ & $\begin{array}{l}3 \\
2\end{array}$ & & $\begin{array}{l}5 \\
\text { 1 }\end{array}$ & $\begin{array}{l}4.5,2,0.5 \\
\mathbf{5}\end{array}$ & $\begin{array}{l}10 \\
\boldsymbol{5}\end{array}$ & $50,20,5$ \\
\hline $\mathrm{O}_{2}$ & & 6 & & 4 & & $\begin{array}{l}5 \\
3\end{array}$ & 20 \\
\hline $\mathrm{O}_{3}$ & $\begin{array}{l}3.75 \\
\times\end{array}$ & 4 & $\begin{array}{l}2.5 \\
\times\end{array}$ & 6 & $\begin{array}{l}2.14 \\
15\end{array}$ & $\begin{array}{l}7 \\
4\end{array}$ & 15 \\
\hline $\mathrm{O}_{4}$ & $\begin{array}{l}0.1 \\
\times\end{array}$ & 50 & $\begin{array}{l}0.1 \\
\times\end{array}$ & 50 & & $\begin{array}{l}50 \\
6\end{array}$ & 5 \\
\hline Demand & 15 & & 30 & & $45,25,10$ & & \\
\hline
\end{tabular}

The concise view of allocation's procedures of the proposed algorithm is shown Table 9. Therefore, total transportation cost of IBFS for the proposed MDWOC-LCM approach is

$$
\begin{aligned}
Z=\sum_{i=1}^{m} \sum_{j=1}^{n} c_{i j} x_{i j} \\
\quad=3 \times 15+5 \times 30+10 \times 5+5 \times 20+7 \times 15+50 \times 5-50 \times 5=\mathbf{4 5 0} .
\end{aligned}
$$

It is observed that in calculating total cost of IBFS the algorithm is able to ignores dummy routes. Here, since $\mathrm{O}_{4}$ is dummy demand so algorithm ignores the transportation cost due to dummy route $\mathrm{O}_{43}$ during calculation of the total Transportation cost.

Now we will find out the IBFSs of the problem by existing LCM as well as DWOC-LCM method. The Table 10 and Table 11 show the IBFSs of the LCM and DWOC-LCM approaches respectively.

Table 10: IBFS of LCM approach

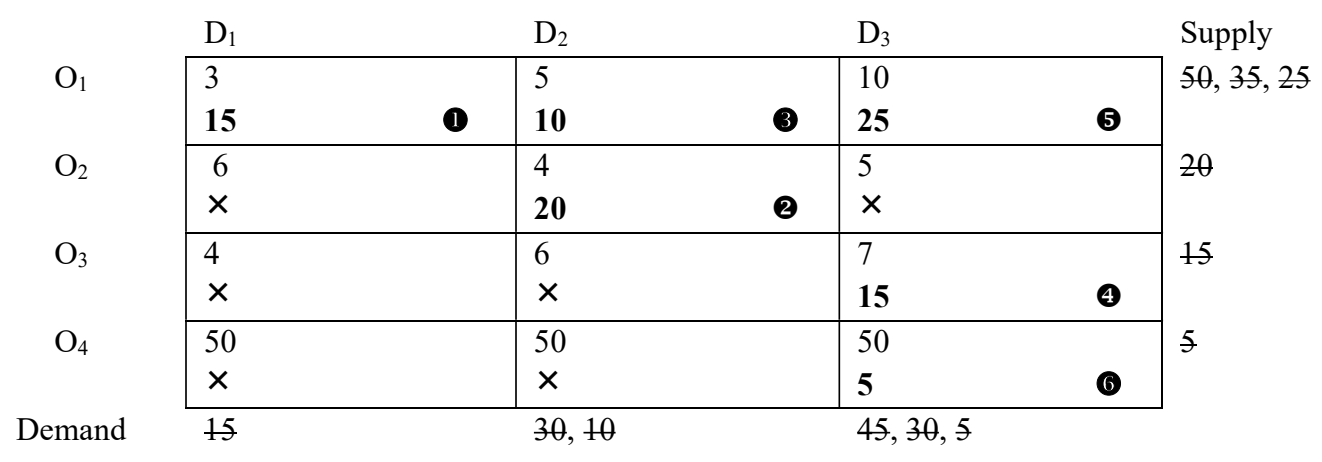

Therefore, total transportation cost of IBFS for LCM method with zero cost corresponding to each dummy route is 


$$
\begin{aligned}
Z=\sum_{i=1}^{m} & \sum_{j=1}^{n} c_{i j} x_{i j} \\
& =3 \times 10+5 \times 10+10 \times 30+4 \times 20+7 \times 15+0 \times 5-0 \times 5=565 .
\end{aligned}
$$

\begin{tabular}{|c|c|c|c|c|c|c|c|}
\hline & $\mathrm{D}_{1}$ & & $\mathrm{D}_{2}$ & & $\mathrm{D}_{3}$ & & Supply \\
\hline $\mathrm{O}_{1}$ & $\begin{array}{l}5,3.33 \\
\mathbf{1 0}\end{array}$ & $\begin{array}{l}3 \\
4\end{array}$ & & $\begin{array}{l}5 \\
2\end{array}$ & $\begin{array}{l}4.5,2,1 \\
\mathbf{1 0}\end{array}$ & $\begin{array}{l}10 \\
6\end{array}$ & $50,20,10$ \\
\hline $\mathrm{O}_{2}$ & $\begin{array}{l}2.5,1.67 \\
\times\end{array}$ & 6 & & 4 & $\begin{array}{l}4 \\
20\end{array}$ & $\begin{array}{l}5 \\
3\end{array}$ & 20 \\
\hline $\mathrm{O}_{3}$ & $\begin{array}{l}3.75,2.5 \\
\times\end{array}$ & 4 & & 6 & $\begin{array}{l}2.14 \\
15\end{array}$ & $\begin{array}{l}7 \\
\mathbf{5}\end{array}$ & 15 \\
\hline $\mathrm{O}_{4}$ & $\begin{array}{l}250 \\
5\end{array}$ & $\begin{array}{l}0 \\
\mathbf{1}\end{array}$ & $\begin{array}{l}250 \\
\times\end{array}$ & 0 & 250 & 0 & 5 \\
\hline Demand & 15,10 & & 30 & & $45,25,10$ & & \\
\hline
\end{tabular}

Table 11: IBFS of DWOC-LCM approach.

Therefore, total transportation cost of IBFS for proposed WOC-LCM method with dummy zero cost,

$$
\begin{aligned}
Z=\sum_{i=1}^{m} & \sum_{j=1}^{n} c_{i j} x_{i j} \\
& =3 \times 10+5 \times 30+10 \times 10+5 \times 20+7 \times 15+0 \times 5-0 \times 5=485 .
\end{aligned}
$$

Now we have compared the proposed approach with other existing approaches for the above example. The experimental results are shown below in the Table 12.

Table 12: Comparison of several approaches regarding total cost for IBFS

\begin{tabular}{|l|c|c|c|c|}
\hline Method & LCM & SUWOC-LCM & MDWOC-LCM & Optimal solution \\
\hline Result & 565 & 485 & $\mathbf{4 5 0}$ & $\mathbf{4 5 0}$ \\
\hline
\end{tabular}

It is observed that the proposed MDWOC-LCM outperforms compared to other approaches. It is also noted that the IBFS obtained by the proposed methods is also optimal. It is also noticed that though the SUWOC-LCM approach performed worse compare to MDWOC-LCM approach but performs much better compared to LCM approaches.

Now we will discuss the allocation procedure of the above-mentioned approaches, namely, LCM, SUWOC-LCM and proposed MDWOC-LCM approaches. It is observed that the first allocation of LCM is at dummy cell, namely, $\mathrm{C}_{41}$ and last allocation is at $\mathrm{C}_{33}$. Again, the first allocation of SUWOC-LCM is at dummy cell namely $\mathrm{C}_{41}$ and last allocation is at $\mathrm{C}_{33}$. On the other hand, the first allocation of MDWOC-LCM is at $\mathrm{C}_{12}$ and last allocation is at $\mathrm{C}_{43}$. That is, in the present of dummy zero cost the existing algorithms are bounded to allocate dummy routes first. Eventually, these algorithms bounded to allocate a large amount of commodities to the destination with larger transportation cost. Again, it is observed that the system will be reversed for dummy highest cost cell. Moreover, in WOC based algorithms allocation procedures are controlled by the WOC matrix. As a result, the total transportation costs of different methods are varied.

\section{FURTHER EXPERIMENTATION AND DISCUSSION}

In order to justify the effectiveness of the proposed approach we have performed further numerical experiments. We have considered 14 randomly generated numerical instances depicted in that second column of Table 13. Off course the problems are unbalanced TPs. For the comparison we have considered the approaches namely LCM, Modified Weighted Opportunity Cost based LCM (MWOC-LCM) and proposed MDWOC-LCM. 
Table 13: Comparison among several approaches for some randomly generated unbalanced TPs

\begin{tabular}{|c|c|c|c|c|c|}
\hline SN & Unbalanced Transportation Problems & MLCM & $\begin{array}{c}\text { MWOC- } \\
\text { LCM }\end{array}$ & $\begin{array}{l}\text { MDWOC } \\
\text {-LCM }\end{array}$ & $\begin{array}{l}\text { Optimal } \\
\text { Solution }\end{array}$ \\
\hline 01. & $\begin{array}{l}C_{i j}=\{(4,3,5),(6,4,8),(5,10,7)\} \\
S=(90,100,120) \\
D=(110,80,160)\end{array}$ & 1720 & 1720 & 1710 & 1550 \\
\hline 02. & $\begin{array}{l}C_{i j}=\{(10,0,20,11),(12,7,9,20) \\
(0,14,16,18)\} \\
S=(20,25,15) \\
D=(22,15,15,20)\end{array}$ & 369 & 339 & 269 & 328 \\
\hline 03. & $\begin{array}{l}C_{i j}=\{(20,30,25,35,40) \\
(25,35,40,22,30),(15,25,55,20,35)\} \\
S=(500,600,400) \\
D=(220,250,280,300,350)\end{array}$ & 34690 & 35650 & 34670 & 34150 \\
\hline 04. & $\begin{array}{l}C_{i j}=\{(2,4,9),(5,3,4),(3,5,6)\} \\
S=(40,10,5) \\
D=(25,20,35)\end{array}$ & 195 & 175 & 175 & 175 \\
\hline 05. & $\begin{array}{l}C_{i j}=\{(2,5,4),(6,1,2),(4,5,2)\} \\
S=(4,11,6) \\
D=(3,7,6)\end{array}$ & 25 & 25 & 25 & 25 \\
\hline 06. & $\begin{array}{l}C_{i j}=\{(10,5,20,11),(12,7,3,20) \\
(5,14,16,18)\} \\
S=(30,25,23) \\
D=(10,14,15,20)\end{array}$ & 531 & 413 & 413 & 393 \\
\hline 07. & $\begin{array}{l}C_{i j}=\{(1,3,8),(4,2,3),(2,4,5)\} \\
S=(40,10,5) \\
D=(25,20,35)\end{array}$ & 140 & 120 & 120 & 120 \\
\hline 08. & $\begin{array}{l}C_{i j}=\{(2,8,7,3,12),(9,5,6,10,3), \\
(11,4,15,8,8),(10,12,6,20,7)\} \\
S=(250,450,470,330) \\
D=(200,280,320,240,250)\end{array}$ & 5860 & 5860 & 5860 & 5860 \\
\hline 09. & $\begin{array}{l}C_{i j}=\{(20,30,40,50),(35,45,55,65) \\
(12,24,36,48),(15,45,60,30)\} \\
S=(1250,1300,1120,1180) \\
D=(1800,1200,1500,1000)\end{array}$ & 148140 & 148140 & 148140 & 148140 \\
\hline 10. & $\begin{array}{l}C_{i j}=\{(1,3,5),(6,5,4),(8,4,7)\} \\
S=(30,10,5) \\
D=(15,20,35)\end{array}$ & 120 & 120 & 120 & 120 \\
\hline 11. & $\begin{array}{l}C_{i j}=\{(7,4,3),(5,8,10),(9,12,6)\} \\
S=(40,20,70) \\
D=(50,30,90)\end{array}$ & 700 & 700 & 700 & 660 \\
\hline 12. & $\begin{array}{l}C_{i j}=\{(2,4,6),(5,3,4),(3,5,8)\} \\
S=(30,10,5) \\
D=(25,15,35)\end{array}$ & 140 & 135 & 140 & 130 \\
\hline 13. & $\begin{array}{l}C_{i j}=\{(4,3,4),(10,7,5),(8,8,3),(5,6,6)\} \\
S=(11,12,10,22) \\
D=(16,10,14)\end{array}$ & 159 & 159 & 164 & 159 \\
\hline
\end{tabular}




\begin{tabular}{|c|l|c|c|c|c|}
\hline SN & Unbalanced Transportation Problems & MLCM & $\begin{array}{c}\text { MWOC- } \\
\text { LCM }\end{array}$ & $\begin{array}{l}\text { MDWOC } \\
\text {-LCM }\end{array}$ & $\begin{array}{l}\text { Optimal } \\
\text { Solution }\end{array}$ \\
\hline 14. & $\begin{array}{l}C_{i j}=\{(5,7,9,6),(6,7,10,5),(7,6,8,1)\} \\
S=(12,14,20) \\
D=(10,6,8,12)\end{array}$ & 172 & $\mathbf{1 6 8}$ & 172 & 168 \\
& & & & \\
\hline
\end{tabular}

It is clearly observed that both MWOC-LCM and MDWOC-LCM have always outperformed compared to classical LCM approach. It is also observed that out of 14 instances, in three instances, the proposed MDWOCLCM has performed better compared to MWOC-LCM approach. On the other hand, MWOC-LCM approach has performed better compared to MDWOC-LCM approach in other three instances. It is noticed that out of 14 instances, in 8 instances either MWOC-LCM approach or MDWOC-LCM approach is able to find out optimal solution too. It is also noticed that in 4 instances all approaches have identical results which is also optimal.

\section{CONCLUSION}

It is noted that both the existing LCM and WOC-LCM approaches are static and suitable for balanced TPs only. Moreover, though the recently developed MWOC-LCM approach is suitable for both balanced and unbalanced TPs but WOC matrix is static. That is like LCM approach, WOC matrix is not updated after each allocation. On the other hand, in SUWOC-LCM approach, WOC is dynamically updated after each allocation but it is suitable for balanced TPs only. So, we have proposed modified version of this approach named MDWOC-LCM approach to solve both unbalanced TPs as well as balanced TPs which is able to overcome the drawbacks. By considering a numerical instance, we have described the proposed method step by step. We have compared the flow of allocations of the proposed method with some existing methods.

Moreover, for the validity and effectiveness of the proposed MDWOC-LCM approach, a number of randomly generated unbalanced TPs are considered. We have compared the numerical result with existing approaches too. It is observed that most of the time the proposed approach is able to find out better results. Though the proposed methods are able to overcome some drawbacks of the existing methods for finding IBFS, till, in some instances, it fails to find out better results. It is worthwhile to mention here that WOC is a new concept in which supplies/demands play an important role to control the flow of allocations. So, it is expected that more researcher will pay attention on this new concept and able to find out much more significant technique for solving related problems.

\section{ACKNOWLEDGEMENT}

This research work is financially supported by the UGC research project, 2000-2021.

\section{REFERENCES}

Azad, S. M. A. K. \& Hossain, M. B. (2017). A New Method for Solving Transportation Problems Considering Average Penalty. IOSR J. Math. 13, 40-43. https://doi.org/10.9790/5728-1301044043.

Charnes, A. \& Cooper, W. W. (1954). The Stepping Stone Method of Explaining Linear Programming Calculations in Transportation Problems, Management Science, 1(1), 49-69.

Goyal, S. K. (1984). Improving VAM for running Balanced Transportation Problems, Journal of Operational Research Society, 35(12), 1113-1114.

Hitchcock, F. L. (1941). Distribution of a Product from Several Sources to Numerous Localities, Journal of

Mathematical Physics, 20, $224-230$.

Hossain, M. M. \& Ahmed, M. M. (2020). A Comparative Study of Initial Basic Feasible Solution by a Least Cost Mean Method (LCMM) of Transportation Problem. American Journal of Operation Research, 10, 122 131.

Hosseini, E. (2017). Three new methods to find initial basic feasible solution of transportation problems. Applied Mathematical Sciences, 11(37), 1803-1814.

Jamali, A. R. M. J. U. \& Akhtar, P. (2018). Sequentially Updated Weighted Cost Opportunity Based Algorithm in Transportation Problem. GANIT: Journal of Bangladesh Mathematical Society, 38, 47-55.

Jamali, A. R. M. J. U., Jannat, F., \& Akhtar, P. (2017). Weighted Cost Opportunity Based Algorithm for Initial Basic Feasible Solution: A New Approach in Transportation Problem. Journal of Engineering, 8(1), $63-$ 70. 
Jamali, A. R. M. J. U., Mondal, R. R. \& Reza, A. K. M. S. (2019) Weighted Cost Opportunity Based Algorithm for Unbalanced Transportation Problem, Proceedings of the $5^{\text {th }}$ International Conference on Engineering Research, Innovation and Education (ICERIE), 25-27 January, SUST, Sylhet, Bangladesh, pp. 525-530.

Kaur, L., Rakshit, M. \& Singh S. (2019). An Another Approach for Obtaining Initial Basic Feasible Solution of Transportation Problem. Research View International Journal of Multidisciplinary,04, 1633-1638.

Koopmans, T. C. (1947). Identification Problems in Economic Model Construction, Conometrica, Journal of the Econometric Society, 17(2), 125-144.

Korukoğlu, S., \& Balli, S. (2011). An Improved Vogel's Approximation Method for the Transportation Problem. Mathematical and Computational Applications, 16(2), 370-381.

Kragul. K. \& Sahin, Y. (2020). A Novel Approximation Method to Obtain Initial Basic Feasible Solution of Transportation Problem. Journal of King Saud University, 32, 211-218.

Reinfeld, N. V., \& Vogel, W. R. (1958). Mathematical Programming New Jersey Prentice Hall. Englewood Cliffs.

Ramakrishnan, G. S. (1988) An Improvement to Goyal's modified VAM for the Unbalanced Transportation Problem, Journal of Operational Research Society, 39(6), 609-610.

Soomro, A. S., Junaid, M., Tularam, G. A., Science, C., Scholar, M. P., Science, C., Lecturer, S., Engineering, S.E., (2015). Modified Vogel's Approximation Method for Solving Transportation Problem. Math. Theory Model. 5, 32-43.

(C) 2021 the Authors. Journal of Engineering Science published by Faculty of Civil Engineering, Khulna University of Engineering \& Technology. This is an open access article under the terms of the Creative Commons AttributionNonCommercial-NoDerivatives License, which permits use and distribution in any medium, provided the original work is properly cited, the use is non-commercial and no Modifications or adaptations are made. 